\title{
Juniperus oxycedrus Leaf Oil
}

National Cancer Institute

\section{Source}

National Cancer Institute. Juniperus oxycedrus Leaf Oil. NCI Thesaurus. Code C74296.

The essential oil extracted from the foliage of Juniperus oxycedrus. 